\title{
Fatigue of Yttria-Stabilized Zirconia: I, Fatigue Damage, Fracture Origins, and Lifetime Prediction
}

\author{
Shin-Yu Liu* and I-Wei Chen* \\ Department of Materials Science and Engineering, The University of Michigan, \\ Ann Arbor, Michigan 48109-2136
}

\begin{abstract}
Uniaxial tension-compression fatigue behavior of 3-mol\%yttria-stabilized tetragonal zirconia polycrystals was investigated. Hysteresis in the stress-plastic strain curve featured cumulative plastic strain and weakened elastic stiffness. Fracture statistics in terms of cycle-to-failure depends strongly on the maximum stress and less on the stress amplitude. Preexisting processing flaws were identified as the fracture origins in all cases. We suggest that microcracking is the dominant mechanism of fatigue damage, that nucleation of fatigue crack is usually not necessary, and that fatigue lifetime is primarily controlled by crack propagation, which is most sensitive to the maximum stress. [Key words: fatigue, fracture, zirconia, cracks, stress.]
\end{abstract}

\section{Introduction}

$\mathbf{F}$ ATIGUE of ceramics, which involves the degradation of mechanical properties of ceramic materials under cyclic loading conditions, has received increasing attention in recent years. The majority of studies reported to date were on bending fatigue using smooth specimens, ${ }^{1-15}$ and on fatigue crack growth using compact tension specimens. ${ }^{16-22}$ These experiments have provided direct evidence of mechanical fatigue effects in ceramics. Nevertheless, mechanistic understanding of fatigue damage and a methodology for lifetime prediction are still lacking. Current understanding of fatigue behaviors in other engineering materials such as metals and polymers ${ }^{23}$ states that nucleation of fatigue damage is surface related and mostly controlled by the amplitude of cyclic strain. On the other hand, propagation of a fatigue crack is divided into three regimes (threshold, striation controlled, and fast fracture), each having a rather different dependence on loading, material, and environmental parameters. Fatigue lifetime prediction can proceed by following a conservative methodology considering crack growth only, or by a more realistic methodology allowing for both nucleation and growth. The intent of the present paper and its companion paper is to provide a better understanding of fatigue in ceramics and to relate it to the above concepts developed for other engineering materials. In the present paper we will focus on the results of uniaxial tension-compression experiments using smooth-surfaced specimens. Fatigue crack growth experiments using specimens with controlled flaws will be described in the companion paper. ${ }^{24}$

Uniaxial, tension-compression fatigue experiments are conducted in the present study to clarify the role of crack

D. Marshall-contributing editor

Manuscript No. 197314. Received September 7, 1990; approved February 28,1991 .

Presented at the 91st Annual Meeting of the American Ceramic Society, Indianapolis, IN, April 25, 1989 (Basic Science Division, Paper No. 77 -

B-89).

Supported by the U.S. National Science Foundation under Grant No. DMR-8807024

*Member, American Ceramic Society. nucleation, surface effects, and fracture statistics in the fatigue of ceramics. With few exceptions, ${ }^{25-27}$ many previous fatigue experiments on smooth specimens were conducted in bending. These experiments suffer from several fundamental drawbacks, which are all related to the fact that the maximum stress in bending falls on the specimen surface, so that fatigue damage is by necessity surface-related. It is thus impossible to ascertain whether surface nucleation of fatigue cracks is a general and preferred mode of fatigue damage. As will become clear later in this paper, fatigue damage does not seem to originate from the surface in uniaxial tension-compression testing. This being the case, the previous experimental data from bending fatigue collected to date must be regarded as having limited statistical value for the engineering design of realistic structural ceramic components. Furthermore, it is inherently difficult to detect small changes in compliance or accumulation of permanent strains in bending (which may be indicative of fatigue damage), due to the very small sample volume which is being highly stressed. Little information is thus afforded by these experiments regarding the diffuse fatigue damage taking place in the bulk.

Because of the obvious technical difficulties in performing uniaxial, push-pull fatigue experiments on brittle ceramic specimens, considerable emphasis has been placed in the recent past on the attainment of a high degree of alignment, say, of less than $0.5 \%$. This is sometimes achieved at the cost of stress reversal capability, in that several test fixture designs allow tension-tension fatigue tests only. ${ }^{26}$ There has been little justification of attaining such good alignment, however, other than the general and self-evident claim that ceramic materials are brittle and thus susceptible to premature fracture due to the added bending stress resulting from poor alignment. In the course of the present study we have analyzed this issue from the viewpoint of fracture mechanism and fracture statistics in order to determine the necessary alignment. We have also placed more emphasis on precision strain measurements during stress cycling to obtain direct evidence of bulk fatigue damage in the form of irreversible strains and degradation of elastic stiffness.

We have chosen an yttria-stabilized tetragonal zirconia (3Y-TZP) for the present study. Fatigue behavior of two other zirconia ceramics, Mg-PSZ and Ce-TZP, which exhibit extensive plasticity by a mechanically induced phase transformation, ${ }^{28-30}$ have been studied in the past. ${ }^{7,8,10,15,16,18,27}$ On the other hand, 3Y-TZP has only rather limited transformation plasticity. ${ }^{31}$ As a result, its toughness is modest and its strength, which is high, is primarily controlled by the catastrophic propagation of preexisting flaws. ${ }^{32,33}$ Also, unlike the other two zirconia ceramics, it exhibits a steep fracture resistance curve ( $R$-curve) during crack propagation. Its very fine grain size (less than $0.5 \mu \mathrm{m}$ ), nearly cubic symmetry (with a tetragonality of only 1.013), and essentially singlephase composition make available a homogeneous microstructure with very few internal stresses. In this respect, it may be considered to be a model material representative of brittle polycrystalline ceramics. 


\section{Experimental Procedure}

\section{(I) Material}

The material studied was a sintered zirconia containing $3 \mathrm{~mol} \%$ yttria (3Y-TZP) with a grain size of about $0.38 \mu \mathrm{m}$. At this composition, fine-grained 3Y-TZP is known to contain primarily a tetragonal phase plus a small fraction of cubic phase. The chemical composition provided by the manufacturer and some reference mechanical properties measured by us are listed in Tables I and II, respectively. The elastic constant was measured directly by a tensile test. The fracture toughness was measured by an indentation technique. Average bend strength and Weibull modulus were evaluated by 20 four-point-bending tests. These latter properties are representative of fractures originating from surface or nearsurface flaws.

\section{(2) Specimens}

Smooth-surfaced uniaxial test specimens used in this study had a 16-mm gauge length and a 6-mm gauge diameter which was designed according to ASTM E606. ${ }^{34}$ A 220-grit diamond wheel was used to grind the as-received cylindrical bars to specification. In this operation, a large amount of material was removed around the gauge section so that any surface inhomogeneity introduced during sintering would not remain. A final mirror surface finish was obtained by polishing with a 1- $\mu \mathrm{m}$-diamond paste.

\section{(3) Uniaxial Fatigue Testing}

Load-controlled uniaxial low cycle fatigue tests were conducted using a computer-controlled servo-hydraulic testing machine* with a load capacity of $100 \mathrm{kN}$. An axial extensometer having a gauge length of $8 \mathrm{~mm}$ was attached to the central portion of the specimen by two springs. Since the specimen surface was rather hard and smooth, a drop of epoxy ${ }^{\dagger}$ was applied between the knife edge of the extensometer and the specimen to prevent slippage. Since zirconia has a relatively large coefficient of thermal expansion while small strains were measured in the present study, special precautions were taken to minimize the temperature fluctuation of the specimen and the extensometer during the test. A foiltype thermocouple was attached to the specimen to monitor the temperature. Stroke, load, axial strain, and radial strain were simultaneously recorded for each cycle. At the start of each fatigue test, the specimen was first loaded between $\pm 100 \mathrm{MPa}$ for 500 cycles before increasing the peak stress and stress amplitude to the desired values. This small stress cycling procedure was used to calculate the apparent Young's modulus for subsequent use and to condition the extensometers to their secure, stable position. A triangular cyclic stress wave form was used, at a frequency of $1 \mathrm{~Hz}$, for $10^{5}$ cycles or until failure occurred. Fracture surfaces of specimens were examined by scanning electron microscopy to reveal fracture origins and other notable features.

\section{Results}

\section{(1) Measurement of Bending Component}

The amount of specimen bending in uniaxial tensioncompression testing is determined by the alignment of the loading train and particularly the gripping mechanism. In the present study, a precisely aligned hydraulic testing machine with a hydraulically activated gripping system was used. To measure the bending strains, three strain gauges at $120^{\circ}$ intervals were attached to the circumference of the specimen. The maximum bending strain was calculated using ${ }^{35}$

$$
\left|\varepsilon_{\mathrm{b}}\right|=(2 / 3)\left[\left(\Delta \varepsilon_{1}\right)^{2}+\left(\Delta \varepsilon_{2}\right)^{2}-\Delta \varepsilon_{1} \Delta \varepsilon_{2}\right]^{1 / 2}
$$

${ }^{*}$ MTS 810 , MTS Systems Corp., Minneapolis, MN

${ }^{\dagger}$ Super Bonder 495, Loctile Corp., Newington, CT
Table I. Chemical Composition of 3Y-TZP*

\begin{tabular}{cc}
\hline Component & Amount (wt\%) \\
\hline $\mathrm{Y}_{2} \mathrm{O}_{3}$ & 5.25 \\
$\mathrm{Al}_{2} \mathrm{O}_{3}$ & 0.066 \\
$\mathrm{SiO}_{2}$ & 0.015 \\
$\mathrm{Fe}_{2} \mathrm{O}_{3}$ & 0.009 \\
$\mathrm{Na}_{2} \mathrm{O}$ & 0.002 \\
$\mathrm{ZrO}_{2}$ & Balance \\
\hline *Product of Tosoh Manufacturing Co., Tokyo, Japan.
\end{tabular}

where $\varepsilon_{\mathrm{b}}$ is the maximum bending strain, and $\Delta \varepsilon_{1}$ and $\Delta \varepsilon_{2}$ are the differences between any two measured strains from the three gauges. The calculated maximum bending strain according to Eq. (1) for a typical tension-compression cycle is shown in Fig. 1. At an axial stress of $300 \mathrm{MPa}$, the bending strain is about $2 \%$ of the axial strain. This value is comparable to those achieved by other workers using other gripping systems. ${ }^{25,26}$ From Fig. 1, the bending stress can be calculated and is found to be below $10 \mathrm{MPa}$ at an axial stress of $600 \mathrm{MPa}$, which was the maximum stress used in the fatigue experiment in the present study.

\section{(2) Hysteresis Loop}

For metals, the hysteresis loop is customarily constructed by plotting the stress-strain response for each cycle. ${ }^{23}$ This practice is not suitable for ceramics, whose plastic strain is just a small portion of the total strain. This is apparent from the stress-strain curve of a typical tensile test, through fracture, as shown in Fig. 2. Note that the total plastic strain at fracture is only $2.2 \times 10^{-4}$, whereas the elastic strain calculated from $\sigma / E_{\text {apparent }}$ is $3.5 \times 10^{-3}$. ( $\sigma$ is applied stress and $E_{\text {apparent }}$ is the apparent Young's modulus determined from the slope of the linear stress-strain curve at an amplitude of ( $\pm 100 \mathrm{MPa}$ at the start of each experiment.) Thus, the elastic strain amplitude is much larger than the plastic strain amplitude in this material.

An alternative way to illustrate the hysteresis during fatigue is to plot the stress against the plastic strain. In Fig. 3, the hysteresis loop of the first cycle and two later cycles, at the same stress amplitude, are plotted. Several features of these loops are noteworthy and are exemplified by the schematic hysteresis loops shown in Fig. 4. The initial rise of the stress-plastic strain loop is vertical in these plots because no plastic strain is involved. This is most evident in Fig. 3 in the first cycle with a pristine specimen. The subsequent curving indicates plastic deformation, which is obvious in all of the loops in Fig. 3. During unloading, the initial portion should be vertical as well, if the stiffness of the ceramic remains unchanged (Fig. 4(a)). A positive slope, on the other hand, would indicate a decrease in elastic stiffness. The latter seems to be the case in Fig. 3 (also Fig. 4(b)) and will be attributed to microcracking, as discussed later. Finally, when the stress decreases to a sufficiently low level, a smaller decrease in plastic strain, corresponding to a recovery of elastic stiffness, can be seen in Fig. 3 (also Fig. 4(c)). This may be attributed to the closure of microcracks.

The hysteresis loops shown in Fig. 3 demonstrate an accumulation of plastic strain. This is possible because of new damage created in successive cycles. The reloading is expected to be elastic initially. If the elastic stiffness is the same as that of the previous unloading cycle, the hysteresis loops should appear as shown schematically in Fig. 4(d). However, the loading portions of all the hysteresis loops in Fig. 3 are actually vertical, which means an undegraded elastic stiffness

Table II. Properties of 3Y-TZP at Room Temperature

\begin{tabular}{ccccc}
\hline $\begin{array}{c}\text { Elastic } \\
\text { modulus } \\
(\mathrm{GPa})\end{array}$ & $\begin{array}{c}\text { Poisson's } \\
\text { ratio }\end{array}$ & $\begin{array}{c}\text { Fracture } \\
\text { toughness } \\
\left(\mathrm{MPa} \cdot \mathrm{m}^{1 / 2}\right)\end{array}$ & $\begin{array}{c}\text { 4-point bend } \\
\text { strength } \\
(\mathrm{MPa})\end{array}$ & $\begin{array}{c}\text { Weibull } \\
\text { modulus }\end{array}$ \\
\hline 210 & 0.33 & 5.33 & $849 \pm 65^{*}$ & 15.98 \\
\hline *Standard deviation. & & &
\end{tabular}




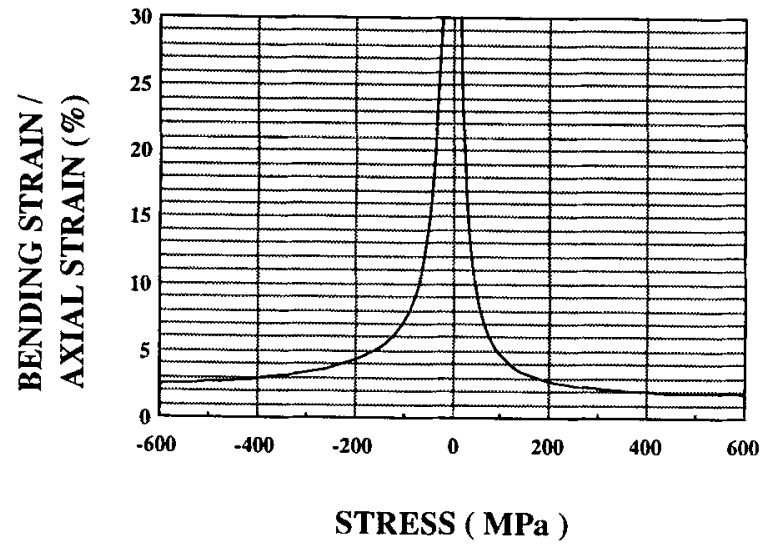

Fig. 1. Ratio of bending strain to axial strain vs axial stress.

(higher than that of the previous unloading cycle). This would be explicable if a friction that opposes the reversal of plastic deformation exists in the material. Such friction may again come from closure of microcracks and the reverse sliding between contact surfaces. A schematic of such hysteresis loops is shown in Fig. 4(e).

\section{(3) Damage Accumulation}

After unloading to zero stress, the hysteresis loop was found to remain at a finite residual strain. In Fig. 5 the accumulated axial plastic strain is plotted against fatigue cycle for a number of experiments. (In this figure, the $R$ ratio refers to the ratio of the minimum stress to the maximum stress during cycling.) The accumulation slows down considerably with the number of cycles. Meanwhile, the same $R$ ratio, an increase in maximum tensile stress, which means increases in both mean stress and stress amplitude, causes more accumulated plastic strain. Note also that at the same maximum stress, an increase of $R$ ratio (corresponding to a decrease of stress amplitude) actually results in a higher damage. Thus, a higher mean stress is more damaging than a higher stress amplitude. This can be further demonstrated by a good correlation between the accumulated plastic strain and the mean stress, shown in Fig. 6 by plotting the plastic strain accumulated after the first 1000 cycles against mean stress for all positive $R$ ratios. The relatively large scatter of data in Figs. 5 and 6 is mostly due to temperature fluctuation during long-time test.

There is a corresponding decrease of the elastic stiffness as the fatigue damage accumulates. This is already apparent in Fig. 3, where we note the decrease of the initial unloading slope as the number of cycles increases $\left(S_{1}>S_{2}>S_{3}\right)$. To demonstrate this effect, we have plotted additional data on elastic stiffness, measured from the initial unloading slope,

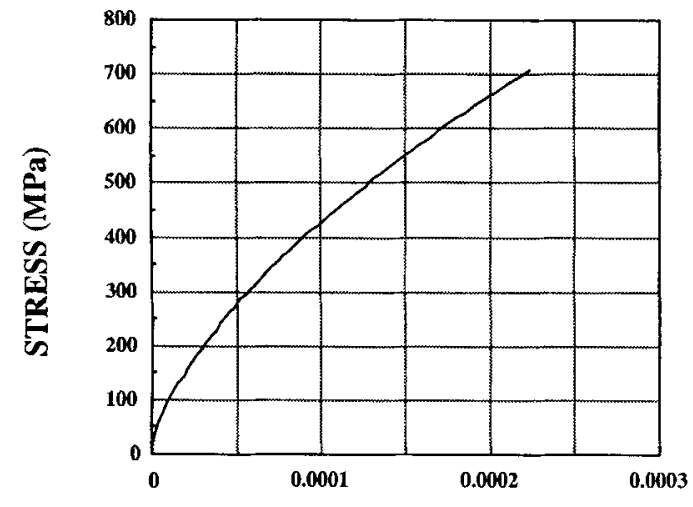

PLASTIC STRAIN

Fig. 2. Stress-plastic strain curve in uniaxial tension.

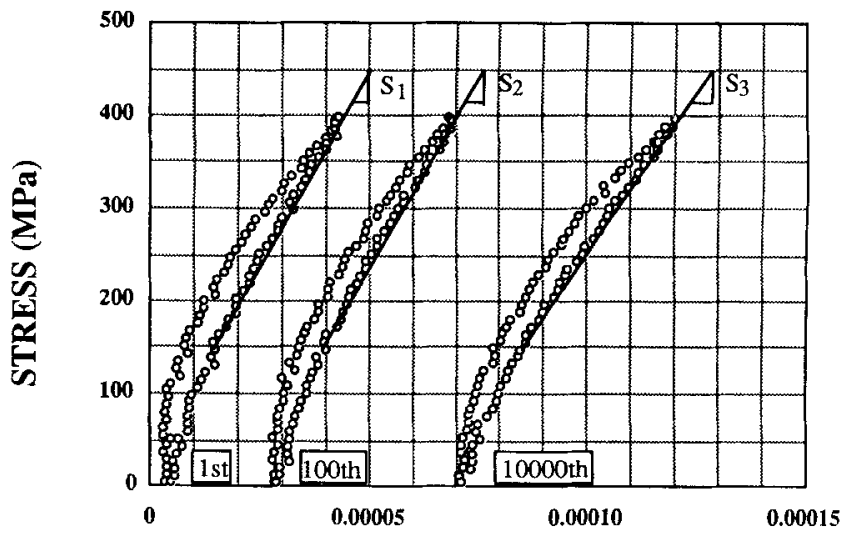

PLASTIC STRAIN

Fig. 3. Hysteresis loops of 3Y-TZP. Note the slope change $\left(S_{1}>S_{2}>S_{3}\right)$ and the shift of loops due to strain accumulation.

against fatigue cycles in Fig. 7. The change in elastic stiffness is of the order of $1 \mathrm{GPa}$ or $0.5 \%$ over the duration of the test.

It should be pointed out that while the strain accumulation can be deemed as direct evidence of damage accumulation, its absence does not necessarily imply the lack of damage. In the extreme case of $R=-1$, not shown in Fig. 5, we have found very little strain accumulation, even though the hysteresis loops expand under increasing stresses and are very prominent at high peak stresses. Data on fracture statistics to be presented next also indicate more severe damage at lower $R$-ratio loading when the maximum stress is kept constant. It is in this sense that the information of Fig. 7 on stiffness degradation is more direct and definitive for assessing damage.

The specimen surface of the fatigued specimen was examined after testing. Before catastrophic failure, there was no evidence of surface damage in the form of microcracks or deformation bands. No trace of monoclinic phase was detected by $\mathrm{X}$-ray diffraction.
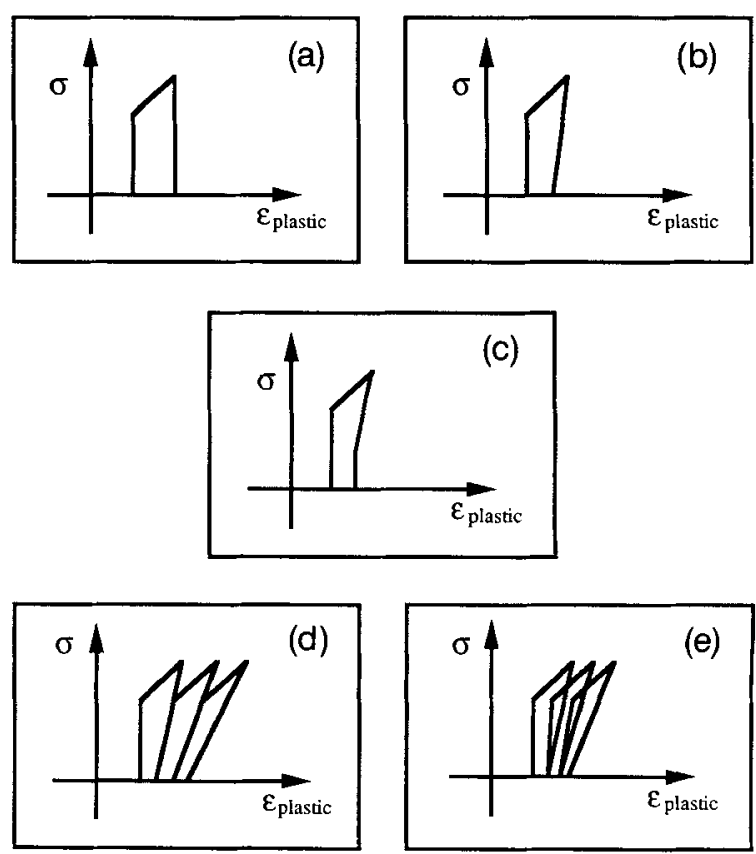

Fig. 4. Schematic hysteresis loops: (a) unloading modulus = loading modulus; (b) unloading modulus < loading modulus; (c) same as (b) but later with crack closure; (d) same as (b) but with further damage during reloading; (e) same as (d) but with crack closure or friction during reloading. 


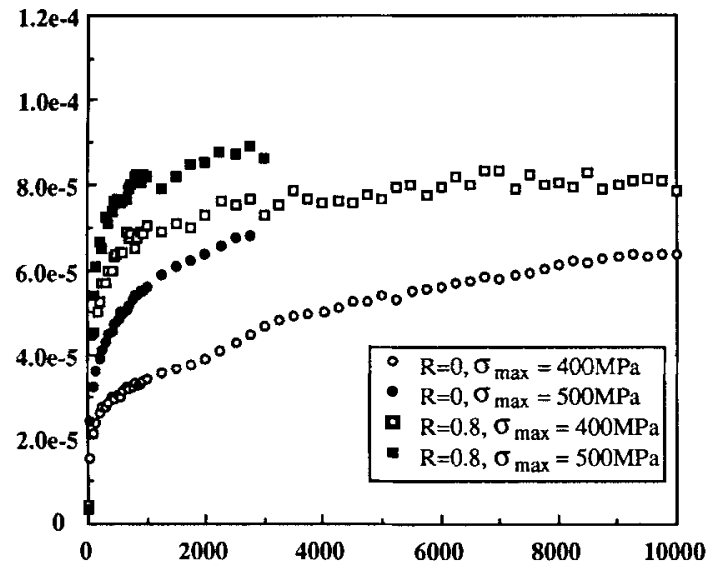

\section{CYCLES}

Fig. 5. Cumulative plastic strain vs cycles.

\section{(4) Fracture Statistics}

For a runout cycle of $10^{4}$, failure loci are plotted in stress amplitude and mean stress as shown in Fig. 8. Diagrams of this kind are named after Goodman in the literature. ${ }^{23}$ The $R$ ratios are indicated on the graph. In the figure, numbers next to the symbols indicate the number of specimens tested. They fall into three categories: all failed after $10^{4}$ cycles, all survived, and some survived. From these statistics, a failure locus can be drawn. The failure locus may be represented by the so-called Goodman relation, ${ }^{23}$ graphically shown by the solid line with a negative slope in Fig. 8, which is

$$
\sigma_{\mathrm{a}}=\sigma_{\mathrm{e}}\left[1-\left(\sigma_{\mathrm{m}} / \sigma_{\mathrm{u}}\right)\right]
$$

where $\sigma_{\mathrm{a}}$ is stress amplitude, $\sigma_{\mathrm{e}}$ is fatigue strength at $R=-1$, $\sigma_{\mathrm{m}}$ is mean stress, and $\sigma_{\mathrm{u}}$ is tensile strength. Several special cases are noted here. First, if fatigue life is governed by the maximum stress only, then the failure locus should be a straight line with a slope of -1 (maximum stress $=$ mean stress + stress amplitude). Second, if only the stress amplitude is of consequence, then the fatigue failure locus should be a horizontal line. The experimental results show that the slope is -0.8 ; i.e., failure is mostly controlled by the maximum stress.

The $S-N$ curves plotted as cycle to failure $\left(N_{\mathrm{f}}\right)$ vs the stress amplitude are shown in Fig. 9 on a $\log -\log$ scale. This form is

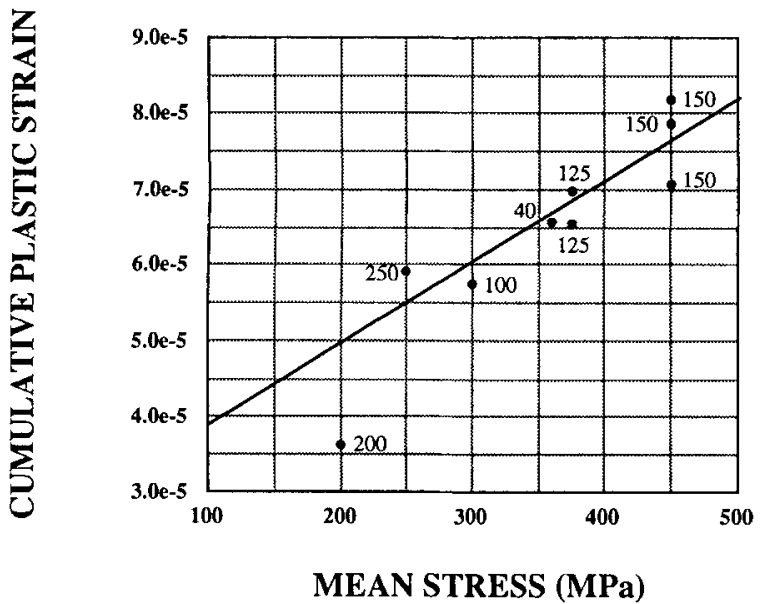

Fig. 6. Cumulative plastic strain after $10^{3}$ cycles vs mean stress Numbers next to the data points indicate the values of the stress amplitude.

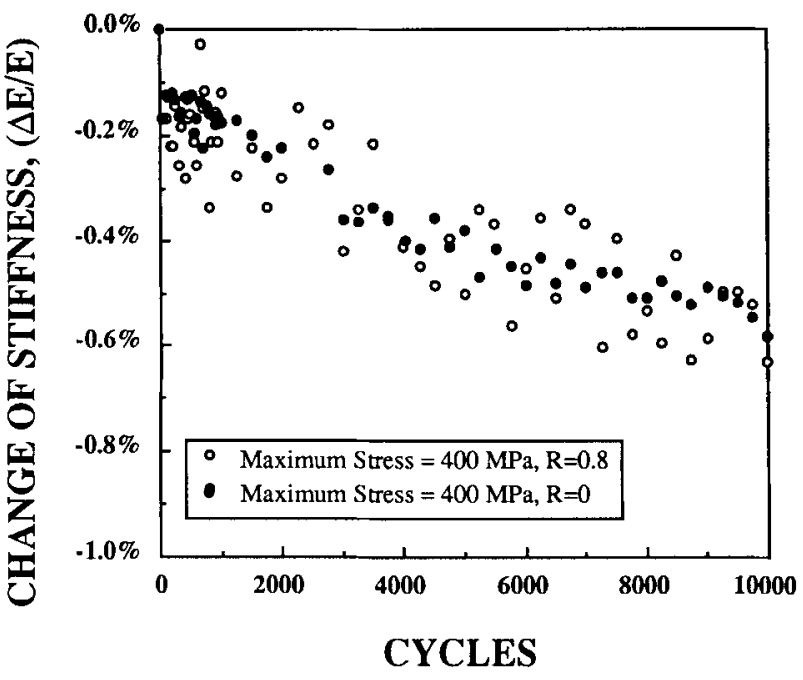

Fig. 7. Normalized stiffness decrease vs fatigue cycles.

a slight modification of the conventional $S-N$ curve, which is normally plotted on a semilog scale. The most notable feature of these curves is that they are actually straight lines with the same slope for all the $R$ ratios. Thus, these data can be represented by the following expression:

$$
\log \left(N_{\mathrm{f}}\right)=-m \log \left(\sigma_{\mathrm{a}}\right)+\log (Z / A)
$$

where $N_{\mathrm{f}}$ is cycles to failure, $m$ is the reciprocal slope of Fig. 9, and $Z / A$ is a constant whose value depends on the $R$ ratio. From Fig. 9 we find $m$ to be around 21 . The values of $Z / A$ are listed in Table III.

\section{(5) Fractography}

Several typical fatigue fracture surfaces of 3Y-TZP are shown in Fig. 10. They allow for easy identification of the fracture origins, but the finer features are indistinct in most cases. At higher magnification, it was verified that the fracture path was always intergranular. Although fracture origins near the center of the fracture surface were found to be relatively infrequent, one such example is shown in Figs. 10(a) and (b). Among near-surface flaws, both closed pores (Figs. 10(c) and (d)) and ones connected to the free surface (Figs. 10(e) and (f)) have been identified as the crack origins. The appearance of these fracture origins suggests that they

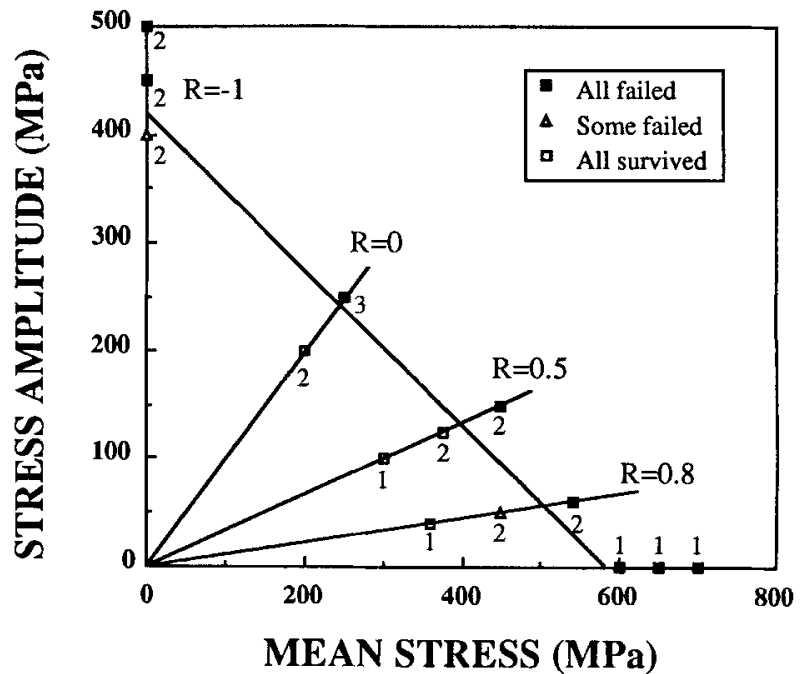

Fig. 8. Goodman diagram of 3Y-TZP for specimens tested for $10^{4}$ cycles. Numbers next to the symbols indicate the number of specimens tested. 


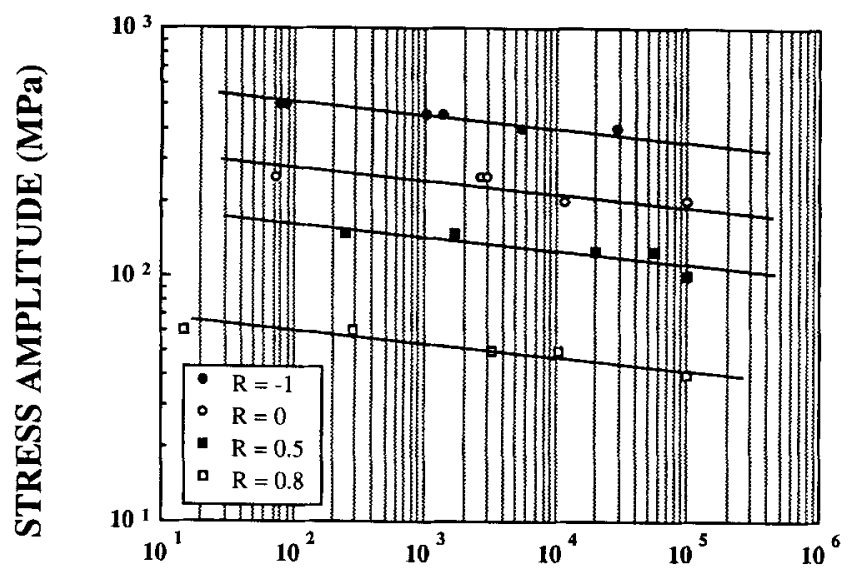

\section{FAILURE CYCLE}

Fig. 9. Stress amplitude-failure cycle $(S-N)$ curve of 3Y-TZP. Tests terminated at $10^{5}$ cycles if failure did not occur.

formed during or before sintering and not by machining. Lastly, we did not find these near-surface fracture origins to be concentrated on a particular side of the specimens, which would have indicated any systematic bending effect due to misalignment.

The fracture surface was also examined by X-ray diffraction. A certain amount of monoclinic phase, of the order of $30 \%$, was observed. However, the phase fraction on the fatigue fractured surfaces was no different from that on uniaxially overloaded fracture surfaces from tensile test specimens.

\section{Discussion}

\section{(1) Alignment and Fracture Statistics}

During uniaxial testing of brittle materials, bending stresses due to misalignment may cause premature failure. Whether this is a serious problem in practice, however, is dependent on the magnitude of bending stresses relative to the statistical scatter of strength. Clearly, if the bending stress is much smaller than the statistical scatter, it would have little effect on the measured strength values. If the four-point bend specimen data of Table I are used as a reference, then the standard deviation in the bend strength of $3 \mathrm{Y}-\mathrm{TZP}$ is $65 \mathrm{MPa}$. In comparison, the misalignment in the present study causes a much smaller bending stress, namely, $10 \mathrm{MPa}$ in the worst case. Thus, an even better alignment would not have any significant effect on the measured strength values, which is subject to statistical scatter of a much larger magnitude anyway.

Our results do indicate that a majority of specimens failed from fracture origins traceable to some preexisting processing flaws in the near surface region. (Most reported studies of bending fatigue found fracture originating from surface cracks which are either surface initiated or machining flaw initiated. This is not the case here.) The fact that nearsurface flaws tend to initiate fracture more frequently can be explained by their higher effective stress intensity factor compared to a central crack. Consider three circular cracks subject to a uniaxial tensile stress at different locations, as shown in Fig. 11. The effective stress intensity factors can be

Table III. Values of $m, Z$, and $A$ in Eq. (7) for Different $R$ Ratios

\begin{tabular}{ccccc}
\hline$R$ ratio & $m$ & $\log (Z / A)$ & $Z$ & $A^{*}$ \\
\hline-1 & 21 & 58.05 & $1.35 \times 10^{35}$ & $1.20 \times 10^{-23}$ \\
0 & 21 & 52.52 & $1.35 \times 10^{35}$ & $4.06 \times 10^{-18}$ \\
0.5 & 21 & 48.00 & $1.35 \times 10^{35}$ & $1.35 \times 10^{-13}$ \\
0.8 & 21 & 38.87 & $1.35 \times 10^{35}$ & $1.82 \times 10^{-4}$ \\
\hline
\end{tabular}

${ }^{*}$ Values for $A$ given for $\Delta K$ in $\mathrm{MPa} \cdot \mathrm{m}^{1 / 2}$ and $a$ in meters. written as

$$
K_{1}=M \sigma(\pi r)^{1 / 2}
$$

where $r$ is the radius of a circular or semicircular crack and $M$ is a geometric factor which is dependent on the location of the crack. For a circular crack far away from the free surface (Fig. 11(a)), the $M$ value equals $2 / \pi(=0.637)$. As the crack moves toward the free surface (Fig. 11(b)), $M$ increases monotonically. For an $r / w$ ratio of $0.8, M$ becomes 0.708 at point a and 0.647 at point $b{ }^{36}$ As the crack approaches the free surface further, i.e., $r / d$ approaching unity, $M$ at the outer ligament may approach infinity. Similar consideration of a semicircular crack at the surface (Fig. 11(c)) suggests an $M$ value of 0.663 and 0.729 at points $\mathrm{c}$ and $\mathrm{d}$, respectively. Thus, the most severe stress intensity factor of a surface or near-surface crack is about $10 \%$ to $15 \%$ higher than that of a central crack in the bulk. For this reason, a surface or nearsurface crack is more prone to damage. Also, since the stress intensity factor in the ligament just below the surface is always very high, near-surface failure origins can link up with the free surface in the early stage of crack propagation. Such observations have been frequent in our study. Therefore, even though the sintering defects are distributed uniformly throughout the sample, those which are near the surface do tend to develop faster and lead to fracture.

From a statistical point of view, fractures may still originate from a center crack. Fracture origins reponsible for such failure should have a size $20 \%$ to $30 \%$ larger than the mean defect size, so that its stress intensity factor is about $10 \%$ to $15 \%$ higher than that of the latter, in order to compete with near-surface flaws. This can be translated to a decrease of strength of $10 \%$ to $15 \%$ for such specimens. From the Weibull modulus and the standard deviation of bend strength of Y-TZP, the probability for this to occur is deemed significant but not overwhelming, which is roughly consistent with our experience.

\section{(2) The Nature of Fatigue Damage}

Our observations on the hysteresis loop of 3Y-TZP have provided important clues to the nature of fatigue damage in an essentially brittle ceramic. Previous compression studies have indicated a very high yield stress, of the order of $1000 \mathrm{MPa}$, in polycrystalline 3Y-TZP. However, much of the plasticity observed appears to be related to slip and not phase transformation. ${ }^{31}$ Our own experience on compression deformation has also confirmed the existence of a very high compressive yield stress. In view of the above, it seems likely that the microplasticity and the associated fatigue damage observed in our study are from a different origin other than phase transformation and slip.

We believe the most likely mechanism of fatigue damage in 3Y-TZP is microcracking. Such a mechanism would be consistent with the decrease of the elastic stiffness, the closure under a large stress reversal, the friction upon load reversal at stress minimum, and the mean stress dependence of accumulated strain. Both microcracking itself and, perhaps more importantly, the closure and friction which render the plastic strain irreversible are mechanically damaging as demonstrated by the recent crack tip plastic zone calculation of Suresh and Brockenbrough. ${ }^{37}$ Whether microcracks are triggered by phase transformation or slip or simply a maximum local stress which exceeds the crack nucleation threshold is not known. However, they are probably distributed homogeneously in the bulk and are sufficiently severe in order to be detectable by our strain measurement technique.

The density of microcracks can be estimated by noting that, near the end of fatigue lifetime, the tensile elastic constant has decreased by about $1 \mathrm{GPa}$ or $0.5 \%$. If we assume that the more severe microcracks are perpendicular to the tensile axis, then the axial Young's modulus is given by ${ }^{38}$

$$
E=E^{\circ}\left[1-16\left(1-\nu^{2}\right) N a^{3} / 3\right]
$$




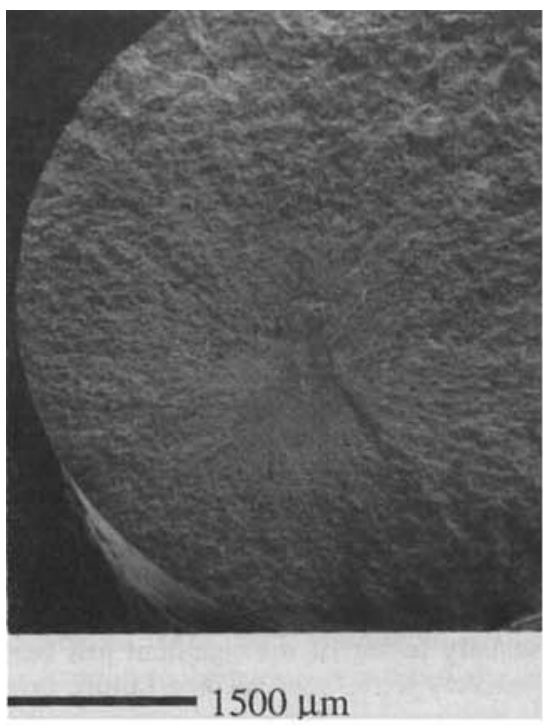

(a)

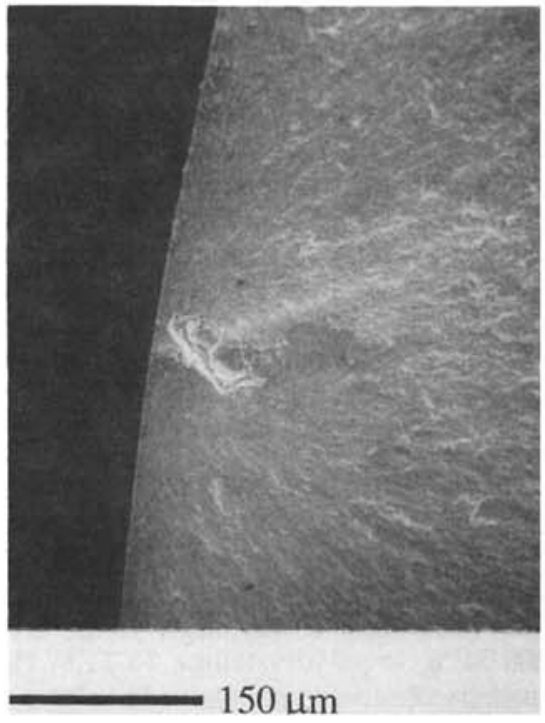

(c)

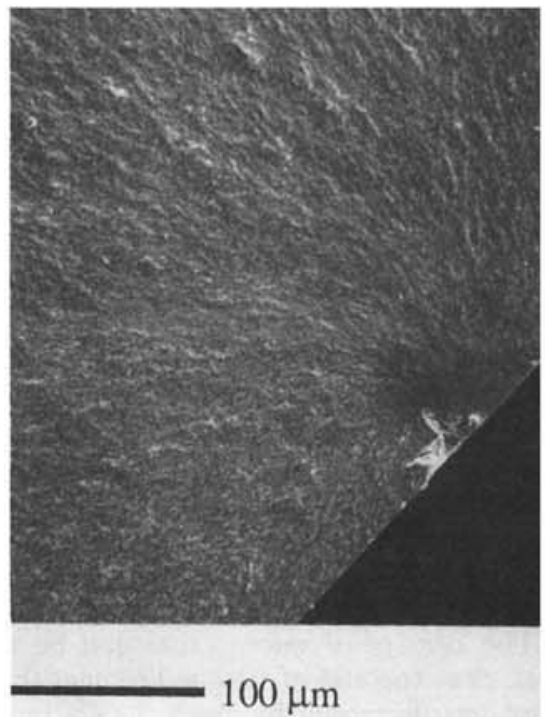

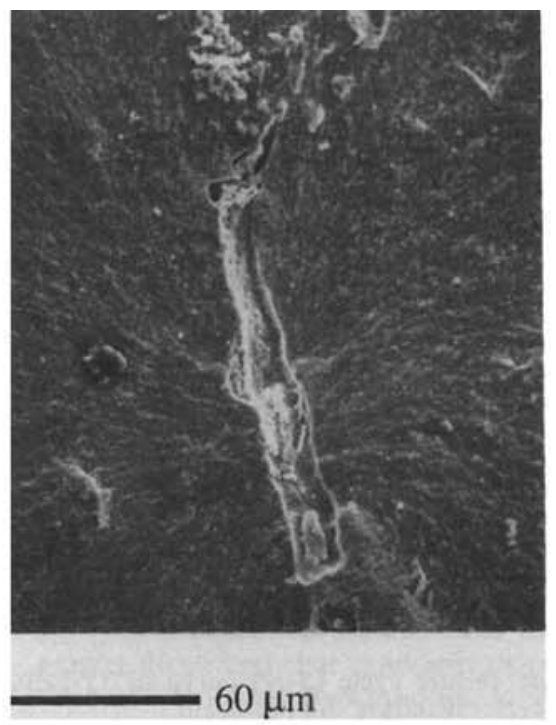

(b)

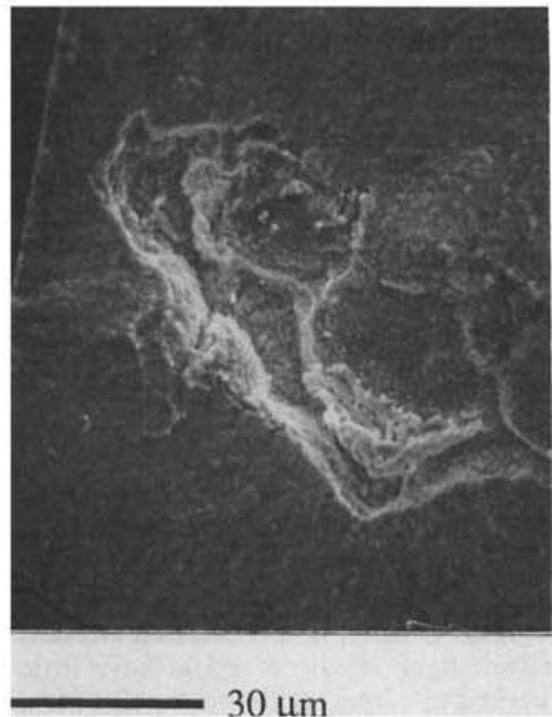

(d)

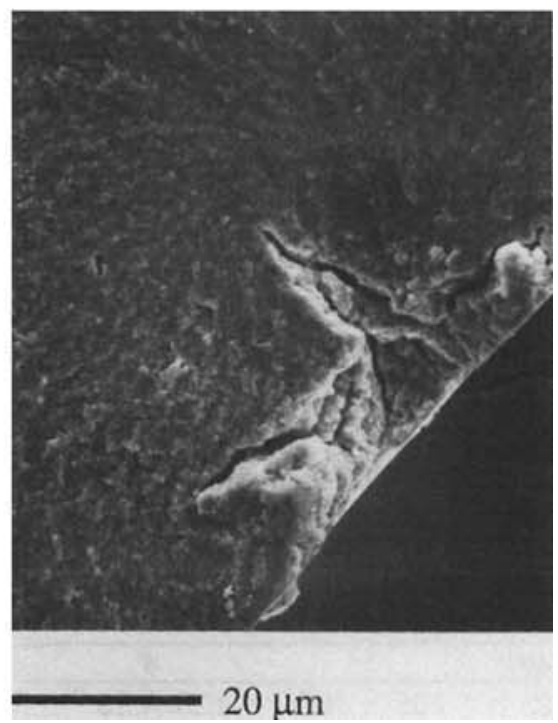

Fig. 10. Fracture origins of fatigue failure in 3Y-TZP: $(a, b)$ a flaw near the center of the specimen; (c, d) a close pore near the surface; $(e, f)$ a surface flaw. 


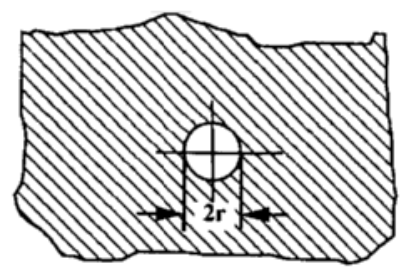

(a)

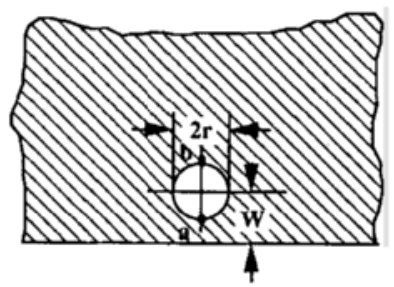

(b)

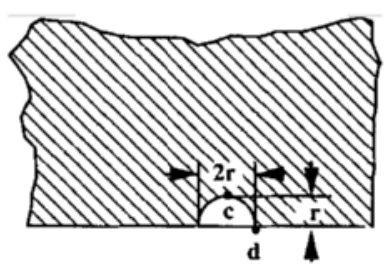

(c)

Fig. 11. Schematic of three circular cracks subjected to uniaxial tension (tensile axis perpendicular to the paper).

where $E^{\circ}$ is the modulus of the uncracked solid, $E$ is the modulus of the microcracked solid, $\nu$ is Poisson's ratio, $N$ is the number density of microcracks, and $a$ is the average radius of microcracks. Taking $\nu=0.3$ for 3Y-TZP, we estimate $\mathrm{Na}^{3}=10^{-3}$. This value represents an average damage in the bulk and is not unreasonable for a fatigue-damaged ceramic just before failure.

It has been customary in the fatigue literature on metals to distinguish two regimes of fatigue in a smooth specimen. ${ }^{23}$ The low cycle fatigue regime is the one where the plastic strain amplitude exceeds the elastic strain amplitude, whereas the high cycle fatigue regime is the one where elastic strain amplitude exceeds the plastic strain amplitude. It has also been established ${ }^{23}$ that in the high cycle fatigue regime, fatigue lifetime is mostly spent in initiating a crack, at the surface, through localized plastic deformation, such as persistent slip bands. Fatigue lifetime in the low cycle fatigue regime, on the other hand, is mostly spent in crack propagation. In the current study, although the plastic component never dominates, there is no evidence that the most severe fatigue damage and the critical flaw ever originate from the free surface, contrary to the case for metals. In the next section, we will further argue that the fatigue lifetime of 3Y-TZP is probably controlled by propagation of preexisting cracks and not by crack initiation as in metals. In other words, fatigue lifetime of 3Y-TZP is ambient temperature is dominated by propagating preexisting cracks while the bulk is still under primarily elastic deformation.

\section{(3) Growth-Controlled Fatigue Life}

The observation in Fig. 9 of $S-N$ curves with a common slope of 21 may be rationalized in the following way (which is a standard treatment for fatigue lifetime under crack growth control) ${ }^{23}$ First, Paris' empirical fatigue growth relation of the following form may be used to estimate the fatigue life:

where $\mathrm{d} a / \mathrm{d} N$ is the fatigue growth rate, $\Delta K$ is the stress intensity range $\left(=2 M \sigma_{\mathrm{a}}(\pi a)^{1 / 2}\right)$, and $A$ and $m$ are constants, which are dependent on material and testing conditions other than the stress intensity factor. By integration

$$
\log \left(N_{\mathrm{f}}\right)=-m \log \left(\sigma_{\mathrm{a}}\right)+\log (Z / A)
$$

where $N_{\mathrm{f}}$ is the cycle to failure and, for $m \neq 2$,

$$
Z=[2 /(m-2)]\left(4 M^{2} \pi\right)^{-m / 2}\left[a_{0}^{(2-m) / 2}-a_{\mathrm{f}}^{(2-m) / 2}\right]
$$

Here, $a_{0}$ is the initial crack length and $a_{i}$ is the final crack length. Thus a linear relationship between $\log N_{\mathrm{f}}$ and $\log \sigma_{\mathrm{a}}$ should result if fatigue lifetime is growth controlled.

The material parameters in Eq. (7) can be directly estimated from Fig. 9. For example, the reciprocal slope gives $m$, and the intercept allows the estimation of $Z / A$. The $m$ value calculated from our experimental data is about 21 . For such a high $m$ value, with $a_{\mathrm{f}}>a_{0}$, the $Z$ value in Eq. (8) is insensitive to $a_{\mathrm{f}}$ and is dependent mostly on the initial crack length $a_{0}$. From Figs. 10 (c) to (f), we estimated an initial length of $25 \mu \mathrm{m}$ for a typical crack flaw. Taking $M=0.65$ for a typical crack located midway between specimen circumference and the center, we estimate $Z$ to be $1.35 \times 10^{35}$. From $Z$, $m$, and the intercept of the $\log \left(\sigma_{\mathrm{a}}\right)-\log \left(N_{\mathrm{f}}\right)$ lines in Fig. 9, the value of $A$ can be computed when $a_{0}$ and $a_{\mathrm{f}}$ are expressed in meters. These results are listed in Table III for different $R$ ratios.

The value of $m$ is rather large compared to data known for metals. However, it is comparable to the ones reported for silicon nitride ${ }^{19}$ and alumina. ${ }^{17}$ Such a large value is thought desirable for engineering applications, since the fatigue strength is relatively close to the monotonic strength for a comparable sample volume under stress. On the other hand, data shown in Fig. 9 are extremely sensitive to the $R$ ratio, much more so than is known for metals. ${ }^{23}$ This strong dependence is of course reflected in the prefactor $A$ evaluated above, which is found to correlate well with $1 /(1-R)$, as shown in Fig. 12. Writing

$$
\log A=m^{\prime} \log [1 /(1-R)]+\log A^{\prime}
$$

where $A^{\prime}$ is another constant, we find $m^{\prime}=19$. Substituting Eq. (9) into Eq. (7) and noting $\sigma_{\mathrm{a}} /(1-R)=\sigma_{\max }$, we find

$$
\begin{aligned}
\log \left(N_{\mathrm{f}}\right)= & -m^{\prime} \log \left(\sigma_{\max }\right)-\left(m-m^{\prime}\right) \log \left(\sigma_{\mathrm{a}}\right) \\
& +\log \left(Z / A^{\prime}\right)
\end{aligned}
$$

Since $m^{\prime} \gg m-m^{\prime}=2$, it is then clear that fatigue strength is primarily controlled by the stress maximum and is weakly dependent (quadratically) on the stress amplitude. In the companion paper, ${ }^{24}$ this dependence will be compared with data on fatigue crack propagation to further assess its validity. The value of $A$ estimated above agrees with the crack growth rate directly measured using controlled surface flaws of several hundred micrometers in size. ${ }^{24}$ This agreement justifies, a

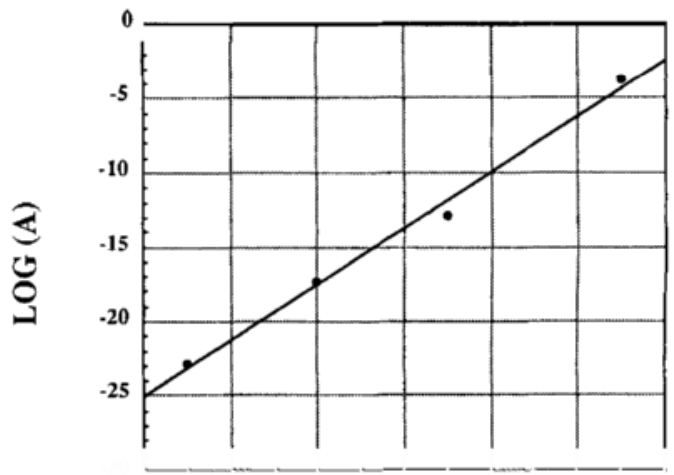

\section{LOG [ 1/(1-R)]}

Fig. 12. Prefactor $(A)$ in crack growth law vs $1 /(1-R)$. 
posteriori, our assumption of using Eq. (6) to estimate the fatigue life.

\section{(4) Implications for Other Ceramics}

Although the present study was conducted for 3Y-TZP, we have reasons to expect that its major findings concerning the nature of fatigue damage in the bulk - the dominance of preexisting flaws and the extreme sensitivity to peak stress-are probably applicable to other ceramics. Our basis for this expectation is founded on the following observations. First, most crystalline ceramics are brittle at ambient temperatures. Thus, their plastic strain in monotonic and cyclic loading is always much smaller than their elastic strain. This seems to rule out the possibility of crack initiation by plastic irreversibility, which tends to be accentuated at the free surface and in deformation bands in metals and polymers. On the other hand, nucleation of microcracks in the bulk can always operate at high stresses, especially when heterogeneous crack nuclei are available. A large internal stress due to thermal mismatch (e.g., in coarse-grained alumina), ${ }^{39}$ elastic anisotropy (e.g., in Mg-PSZ), ${ }^{40}$ or phase transformation (e.g., in $\mathrm{Mg}-\mathrm{PSZ}$ and Ce-TZP) ${ }^{27-30}$ would also favor the latter process for causing fatigue damage. Third, a very strong stress dependence on fatigue strength or, equivalently, a very strong $\Delta K$ dependence on $\mathrm{d} a / \mathrm{d} N$, has been reported in nearly all of the ceramics thus far investigated..$^{1-22}$ This implies a flat $S-N$ curve so that the value of fatigue strength is rather close to the monotonic strength. Therefore, the strength-limiting flaws in fatigue need to grow only a relatively small amount from their original length before catastrophic failure ensues. In other words, the condition seems to favor the growth of preexisting cracks in general rather than the nucleation of new flaws.

\section{Conclusions}

(1) The bending component of less than $3 \%$ during the fully reversed, uniaxial fatigue experiments performed on a 3Y-TZP material has been achieved. This bending effect is insignificant compared to the scatter of strength for a typical, low Weibull modulus ceramic.

(2) Hysteresis observed in the stress-plastic strain curve featured cumulative plastic strain and weakened elastic stiffness. These and other related features can be accounted for by microcracking, which is suggested to be the dominant fatigue damage in ceramics.

(3) Mean stress and stress amplitude dependence of failure statistics followed the Goodman relationship, with a strong bias toward maximum stress control. A similarly strong dependence on the maximum stress has also been observed for $S-N$ curves, which also follow a weaker, quadratic stress amplitude dependence.

(4) Fatigue failure originated from internal, preexisting flaws. Surface nucleation was not observed, but stress concentration due to the surface was important. The prevalent observation of near-surface or surface fracture origins can be attributed to the higher stress concentration of these flaws due to geometrical factors.

(5) Fatigue lifetime is probably controlled by crack propagation. This is consistent with the $S-N$ curve and the fracture origins. A direct confirmation of this point by crack growth rate measurement is reported in the companion paper. ${ }^{24}$

\section{References}

${ }^{1}$ D. A. Krohn and D. P. H. Hasselman, "Static and Cyclic Fatigue Behavior of a Polycrystaltine Alumina," J. Am. Ceram. Soc., 55 [4] 208-11 (1972)

${ }^{2}$ C. P. Chen and W. J. Knapp, "Fatigue Fracture of an Alumina Ceramic at Several Temperatures"; pp. 691-707 in Fracture Mechanics of Ceramics, Vol. 2. Edited by R. C. Bradt, A. G. Evans, D. P. H. Hasselman, and F. F. Lange, Plenum Press, New York, 1973.

${ }^{3} \mathrm{R}$. Kossowsky, "Cyclic Fatigue of Hot-Pressed $\mathrm{Si}_{3} \mathrm{~N}_{4}$," J. Am. Ceram. Soc., 56 [10] 531-55 (1973).

${ }^{4} \mathrm{H}$. N. Ko, "Fatigue Strength of Sintered $\mathrm{Al}_{2} \mathrm{O}_{3}$ under Rotary Bending,"
J. Mater. Sci. Lett., 5, 464-66 (1986)

${ }^{5}$ H. N. Ko, "Cyclic Fatigue Behavior of Sintered $\mathrm{AI}_{2} \mathrm{O}_{3}$ under Rotary Bending," J. Mater. Sci. Lett., 6, 801-805 (1987).

'I. Maekawa, H. Shibata, and A. Kobayashi, "Bending Fatigue of $\mathrm{Al}_{2} \mathrm{O}_{3}-$ $\mathrm{ZrO}_{2}$ Ceramics," J. Soc. Mater. Sci., Jpn., 36 [409] 1116-27 (1987).

"M.V. Swain and V. Zelizko, "Comparison of Static and Cyclic Fatigue on Mg-PSZ Alloys"; pp. 595-606 in Advances in Ceramics, Vol. 24B, Science and Technology of Zirconia III. Edited by S. Sōmiya, N. Yamamoto, and H. Hanagida. American Ceramic Society, Westerville, OH, 1988.

${ }^{8}$ V. Zelizko and M.V. Swain, "Influences of Surface Preparation on the Rotating Flexural Fatigue of Mg-PSZ,"J. Mater. Sci., 23, 1077-82 (1988).

${ }^{9}$ M. Takatsu, H. Kamiya, K. Ohya, K. Ogura, and T. Kinoshita, "Effect of Vibrated Cyclic Fatigue Properties of Ceramics from Stress Load Condition," J. Jpn. Ceram. Soc., 96 [10] 990-96 (1988).

${ }^{10}$ L. A. Sylva and S. Suresh, "Crack Growth in Transforming Ceramics under Cyclic Tensile Loads," J. Mater. Sci., 24, 1729-38 (1989).

${ }^{11}$ M. Masuda, N. Yamada, T. Soma, M. Matsui, and I. Oda, "Fatigue of Ceramics (Part 2)-Cyclic Fatigue Properties of Sintered $\mathrm{Si}_{3} \mathrm{~N}_{4}$ at Room Temperature," J. Jpn. Ceram. Soc., 97 [5] 520-24 (1989).

${ }^{12}$ H. Kamiya, M. Takatsu, K. Ohya, M. Ando, and A. Hattori, "Effect of Microstructure on Cyclic Fatigue Properties of $\mathrm{Al}_{2} \mathrm{O}_{3}$ Ceramics and $\mathrm{Al}_{2} \mathrm{O}_{3}$ Composites," J. Jpn. Ceram. Soc., 98 [5] 456-63 (1990)

${ }^{13}$ M. Takatsu, K. Ohya, and M. Ando, "The Relationship between Cyclic Fatigue Properties and Microstructures of Sintered Silicon Nitride Ceramics," J. Jpn. Ceram. Soc., 98 [5] 490-98 (1990).

${ }^{14}$ A. A. Steffen, R. H. Dauskardt, and R. O Ritchie, "Cyclic FatigueCrack Propagation in Ceramics: Long and Small Crack Behavior" pp. 745-52 in Fatigue 90, Proceedings of the Fourth International Conference on Fatigue and Fatigue Thresholds. Edited by $\mathbf{H}$. Kitagawa and $\mathbf{T}$. Tanaka. Materials and Component Engineering Publications Ltd., Birmingham, U.K., 1990.

${ }^{15}$ D. C. Cardona and C. J. Beevers, "Fatigue Behavior of Zirconia-Ceria Alloys"; pp. 1023-29 in Fatigue 90, Proceedings of the Fourth International Conference on Fatigue and Fatigue Thresholds. Edited by H. Kitagawa and T. Tanaka. Materials and Component Engineering Publications Ltd., Birmingham, U.K., 1990.

${ }^{16}$ R. H. Dauskardt, W. Yu, and R. O. Ritchie, "Fatigue Crack Propagation in Transformation-Toughened Zirconia Ceramic," J. Am. Ceram. Soc., 70 [10] C-248-C-252 (1987).

${ }^{17}$ M. J. Reece, F. Guiu, and M. F. R. Sammur, "Cyclic Fatigue $C_{r a c k}$ Propagation in Alumina under Direct Tension-Compression Loading," $\mathrm{J}$. Am. Ceram. Soc., 72 [2] 348-52 (1989).

${ }^{18}$ R. H. Dauskardt, D. B. Marshall, and R. O. Ritchie, "Cyclic FatigueCrack Propagation in Magnesia-Partially-Stabilized Zirconia Ceramics," J. Am. Ceram. Soc., 73[4] 893-903 (1990).

${ }^{19} \mathrm{H}$. Kishimoto, A. Ueno, and H. Kawamoto, "Crack Propagation Behavior of $\mathrm{Si}_{3} \mathrm{~N}_{4}$ under Cyclic Loads-Influence of Difference in Materials", pp. 727-32 in Fatigue 90, Proceedings of the Fourth International Conference on Fatigue and Fatigue Thresholds. Edited by H. Kitagawa and T. Tanaka. Materials and Component Engineering Publications Ltd., Birmingham, U.K., 1990

${ }^{20}$ A. Ueno, H. Kishimoto, H. Kawamoto, and M. Asakura, "Crack Propagation Behavior of Sintered Silicon Nitride under Cyclic Load of High Stress Ratio and High Frequency"; pp. 733-38 in Fatigue 90, Proceedings of the Fourth International Conference on Fatigue and Fatigue Thresholds. Edited by H. Kitagawa and T. Tanaka. Materials and Component Engineering Publications Ltd., Birmingham, U.K., 1990.

${ }^{21}$ R. H. Dauskardt, W. C. Carter, D. K. Veirs, and R. O. Ritchie, "Transient Subcritical Crack-Growth Behavior in Transformation-Toughened Ceramics," Acta Metall., in press.

${ }^{22}$ J. F. Tsai, C.S. Yu, and D. K. Shetty, "Fatigue Crack Propagation in Ceria-Partially-Stabilized Zirconia (Ce-TZP)-Alumina Composites," J. Am. Ceram. Soc., 73 [10] 2992-3001 (1990).

${ }^{23}$ See, for example, R.W. Hertzberg, Deformation and Fracture Mechanics of Engineering Materials, 3d ed.; pp. 475-604. Wiley, New York, 1989.

${ }^{24}$ S.-Y. Liu and I-W. Chen, "Fatigue of Yttria-Stabilized Zirconia: II, Crack Propagation, Fatigue Striations, and Short-Crack Behavior," J. Am Ceram. Soc., 74 [6] 1206-16 (1991).

${ }^{25}$ M. Masuda, T. Soma, M. Matsui, and I. Oda, "Fatigue of Ceramics (Part I) - Fatigue Behavior of Sintered $\mathrm{Si}_{3} \mathrm{~N}_{4}$ under Tension-Compression Cyclic Stress," J. Jpn. Ceram. Soc., 96 [3] 277-83 (1988).

${ }^{26}$ K. C. Liu, "Tensile Cyclic Fatigue of Structural Ceramics," Proc. 24th Auto. Tech. Development Contractor's Coordination Meeting, 279-83 (1985).

${ }^{27}$ K. J. Bowman, P. E. Reyes-Morel, and I.-W. Chen, "Reversible Transfor mation Plasticity in Uniaxial Tension-Compression Cycling of Mg-PSZ," Mater. Res. Soc. Symp. Proc., 78, 51-58 (1987).

${ }^{28} \mathrm{I}-\mathrm{W}$. Chen and P. E. Reyes-Morel, "Transformation Plasticity and Transformation Toughening in Mg-PSZ and Ce-TZP," Mater. Res. Soc. Symp. Proc., 78, 75-88 (1987).

${ }^{29} \mathrm{I}-\mathrm{W}$. Chen and P. E. Reyes-Morel, "Implications of Transformation Plas ticity in $\mathrm{ZrO}_{2}$-Containing Ceramics: I, Shear and Dilatation Effects," J. Am Ceram. Soc., 69 [3] 181-89 (1986).

${ }^{30}$ P. E. Reyes-Morel and I-W. Chen, "Transformation Plasticity of $\mathrm{CeO}_{2}$ Stabilized Tetragonal Zirconia Polycrystals: I, Stress Assistance and Autocatalysis," J. Am. Ceram. Soc., 71 [5] 343-53 (1988).

${ }^{31}$ J. Lankford, R. A. Page, and L. Rabenberg, "Deformation Mechanisms in Yttria-Stabilized Zirconia," J. Mater. Sci., 23, 4144-56 (1988),

${ }^{32}$ T. Masaki and K. Shinjo, "Mechanical Behavior of $\mathrm{ZrO}_{2}-\mathrm{Y}_{2} \mathrm{O}_{3}$ Ceramics Formed by Hot Isostatic Pressing”; pp. 709-20 in Advances in Ceramics, 
Vol. 24B, Science and Technology of Zirconia III. Edited by S. Sōmiya, N. Yamamoto, and H. Hanagida. American Ceramic Society, Westerville, OH, 1988.

${ }^{33} \mathrm{~K}$. Tsukuma and T. Takahata, "Mechanical Property and Microstructure of TZP and TZP $/ \mathrm{Al}_{2} \mathrm{O}_{3}$ Composites," Mater. Res. Soc. Symp. Proc., 78, 123-35 (1987).

${ }^{34}$ ASTM Standard E.606-80, "Standard Recommended Practice for Constant-Amplitude Low Cycle Fatigue Testing"; pp. 652-69 in ASTM Annual Book of Standards, Vol. 3.01. American Society for Testing and Materials, Philadelphia, PA, 1983.

${ }^{35}$ B.W. Christ and S.R. Swanson, "Alignment Problems in the Tensile Test," J. Test. Eval., 4 [6] 405-17 (1976).
${ }^{36} \mathrm{H}$. Nisitani and Y. Murakami, "Stress Intensity Factors of an Elliptical Crack or a Semi-Elliptical Crack Subject to Tension," Int. J. Fract., 10 [3] 353-68 (1974).

${ }^{37}$ S. Suresh and J.R. Brockenbrough, "Theory and Experiments of Fracture in Cyclic Compression: Single Phase Ceramics, Transforming Ceramics and Ceramic Composites," Acta Metall., 36 [6] 1455-70 (1988).

${ }^{38}$ P. E. Reyes-Morel and I-W. Chen, "Stress-Biased Anisotropic Microcracking in Zirconia Polycrystals," J. Am. Ceram. Soc., 73 [4] 1026-33 (1990).

${ }^{39}$ J. E. Blendell and R. L. Coble, "Measurement of Stress Due to Thermal Expansion Anisotropy in $\mathrm{Al}_{2} \mathrm{O}_{3}, " J$. Am. Ceram. Soc., 65 [3] 174-78 (1982).

${ }^{40}$ D. B. Marshall and M.V. Swain, "Reversible Transformation and Elastic Anisotropy in $\mathrm{Mg}-\mathrm{ZrO}_{2}, " J$. Am. Ceram. Soc., 72 [8] 1530-32 (1989). 